\title{
A Drosophila IкB kinase complex required for Relish cleavage and antibacterial immunity
}

\author{
Neal Silverman, ${ }^{1,4}$ Rui Zhou, ${ }^{1,4}$ Svenja Stöven, ${ }^{2}$, Niranjan Pandey, ${ }^{1,3}$ Dan Hultmark, ${ }^{2}$ \\ and Tom Maniatis ${ }^{1,5}$ \\ ${ }^{1}$ Department of Molecular and Cellular Biology, Harvard University, Cambridge, Massachusetts 02138, USA; ${ }^{2}$ Umeå Center \\ for Molecular Pathogenesis, Umeå University, S-901 87 Umeå, Sweden
}

\begin{abstract}
Here we report the identification of a Drosophila IKB kinase complex containing DmIKK $\beta$ and DmIKK $\gamma$, homologs of the human IKK $\beta$ and IKK $\gamma$ proteins. We show that this complex is required for the signal-dependent cleavage of Relish, a member of the Rel family of transcriptional activator proteins, and for the activation of antibacterial immune response genes. In addition, we find that the activated DmIKK complex, as well as recombinant DmIKKß, can phosphorylate Relish in vitro. Thus, we propose that the Drosophila IкB kinase complex functions, at least in part, by inducing the proteolytic cleavage of Relish. The $\mathbf{N}$ terminus of Relish then translocates to the nucleus and activates the transcription of antibacterial immune response genes. Remarkably, this Drosophila IкB kinase complex is not required for the activation of the Rel proteins Dif and Dorsal through the Toll signaling pathway, which is essential for antifungal immunity and dorsoventral patterning during early development. Thus, a yet to be identified IкB kinase complex must be required for Rel protein activation via the Toll signaling pathway.
\end{abstract}

[Key Words: insect immunity; NF-кB; IKK; Relish]

Received June 30, 2000; revised version accepted August 7, 2000.

NF-кB and other members of the Rel family of transcriptional activator proteins play essential roles in human innate immunity and in the Drosophila immune response (Hoffmann et al. 1999). In most cells Rel proteins are sequestered in the cytoplasm as a result of their association with an inhibitor protein, ІкB. When human cells are infected by a microbial pathogen, signaling pathways are activated, culminating in the proteasomedependent degradation of IкB and the nuclear translocation of NF- $\mathrm{BB}$. Once in the nucleus, NF- $\mathrm{kB}$ activates the transcription of genes encoding antimicrobial proteins (Ghosh et al. 1998). The degradation of IкB is triggered by the activation of the ІкB kinase (IKK) complex (Chen et al. 1996; Lee et al. 1997), containing IKK $\alpha$ and IKK $\beta$, which are both catalytic subunits, and a structural component IKK $\gamma$ (DiDonato et al. 1997; Mercurio et al. 1997; May and Ghosh 1998; Rothwarf et al. 1998; Yamaoka et al. 1998). The activated IкB kinase complex then phosphorylates IкB proteins, leading to their ubiquitination and subsequent degradation by the proteasome (Finco and Baldwin 1995).

\footnotetext{
${ }^{3}$ Present address: R.W. Johnson Pharmaceutical Research Institute, Raritan, NJ 08869, USA.

${ }^{4}$ These authors contributed equally to this work.

${ }^{5}$ Corresponding author.

E-MAIL maniatis@biohp.harvard.edu; FAX (617) 495-3537.

Article and publication are at www.genesdev.org/cgi/doi/10.1101/ $\operatorname{gad} .817800$.
}

Two distinct pathways for the activation of the Drosophila immune response have been identified. Infection by gram-negative bacterial pathogens leads to the production of antibacterial peptides, such as Attacin, Diptericin, and Cecropin, whereas fungal infection leads to the production of antifungals such as Drosomycin (Lemaitre et al. 1997). Three Drosophila Rel proteins are differentially required for the two immune response pathways. The antifungal response activates the Toll signaling pathway, causing the degradation of the ІкB protein Cactus and the activation of two Drosophila Rel proteins, Dorsal and Dif (Lemaitre et al. 1996; Manfruelli et al. 1999; Meng et al. 1999; Rutschmann et al. 2000a). This pathway is triggered by fungal infection, which is believed to cause the activation of a serine protease cascade in the haemolymph. This protease cascade results in the proteolytic processing of Spätzle, the ligand for the transmembrane receptor Toll (Levashina et al. 1999). Activated Toll signals through two proteins, Tube and Pelle, leading to the degradation of Cactus (Belvin and Anderson 1996). Similar to mammalian IкBs, it is thought that Cactus degradation is triggered by phosphorylation of its $\mathrm{N}$-terminal regulatory domain followed by ubiquitination, mediated by the Slimb-containing ubiquitin ligase complex and destruction by the $26 \mathrm{~S}$ proteasome (Spencer et al. 1999). The identity of the Toll-activated Cactus kinase remains unknown. Degra- 
dation of Cactus leads to the nuclear translocation of Dif and Dorsal and the activation of transcription. Interestingly, in larvae either Dif or Dorsal is sufficient for antifungal immunity, whereas in adults Dif is required (Manfruelli et al. 1999; Meng et al. 1999; Rutschmann et al. 2000a). The Toll pathway also plays a critical role in early development, where it is required for dorsoventral patterning of the embryo. Dorsal, but not Dif, is required for the dorsoventral pathway (Belvin and Anderson 1996).

The antibacterial immune response requires the other Drosophila Rel protein, Relish (Hedengren et al. 1999). Relish is a homolog of the mammalian p105 precursor of NF-кB p50 protein. Like its mammalian counterpart, Relish consists of both an N-terminal Rel homology domain (RHD), and a C-terminal IкB-like Ankyrin-repeat domain that is believed to inhibit its own nuclear translocation (Dushay et al. 1996). However, the regulation of Relish appears to be quite different than that of p105. Recently S. Stöven and D. Hultmark found that Relish is activated by endoproteolytic cleavage in response to bacterial infection, leading to the production of the Relish $\mathrm{N}$-terminal RHD, which translocates to the nucleus, and a stable C-terminal Ankyrin domain that remains in the cytoplasm. Furthermore, they have found that this cleavage is not mediated by the proteasome (Stöven et al. 2000). The activation of Relish appears to be the crucial event in the induction of the antibacterial immune response. However, the signaling pathway leading from bacterial infection to Relish cleavage is poorly understood. The cell surface receptors that recognize gramnegative bacteria or their cell wall component lipopolysaccharide (LPS) are unknown. In mammals, the Toll family of receptors, and TLR4 in particular, have been shown to be involved in LPS recognition and signaling, although none of the eight Drosophila Toll family members have yet been shown to be an LPS receptor (Medzhitov and Janeway 2000). Furthermore, the components and mechanisms used to transduce the signal from the cell surface receptors to Relish have not yet been identified. Here we identify and characterize a Drosophila IкB kinase complex that is activated by LPS and is in turn required for the activation of antibacterial immune response genes and for the LPS-dependent cleavage of Relish. Furthermore, we show that the activated kinase is capable of phosphorylating Relish in vitro. However, this Drosophila IKK complex is not required for the Toll signaling pathway, which is necessary for antifungal immunity and early embryonic dorsoventral patterning.

\section{Results}

To identify the signaling components required for the Drosophila immune response we have undertaken a reverse genetic approach, taking advantage of the Drosophila Genome Project. A cDNA sequence with homology to the kinase domain of the human IKK genes was identified in the BDGP EST database (Berkeley Drosophila Genome Project/HHMI EST Project, unpubl.). Examination of the amino acid sequence of the encoded protein, which we designate DmIKK $\beta$ (Drosophila melanogaster IKK $\beta$ ), displays significant similarity to the $\mathrm{N}$ terminal region of hIKK $\alpha$ and hIKK $\beta$ but is more similar to hIKK $\beta$. The amino acid sequence of the $\mathrm{C}$ terminus of $\operatorname{DmIKK} \beta$ is only weakly related to the corresponding regions of IKK $\alpha$ and IKK $\beta$. A predicted coiled-coil can be detected in a region corresponding to the predicted leucine zipper coiled-coil of hIKK $\alpha$ and hIKK $\beta$ (Fig. 1A). The $D m I K K \beta$ gene maps to chromosomal location $89 \mathrm{~B}$ as determined with the BDGP P1 filter array (Kimmerly et al. 1996). While this manuscript was in preparation, Kim et al. (2000) reported the initial characterization of the same gene, which they refer to as $D L A K$. They report that the autophosphorylation of $D L A K$ is inducible by LPS, and they present evidence that Cactus may be a target of the kinase. In addition, they show that expression of a dominant negative mutant of $D L A K$ inhibits the LPS-dependent activation of Rel proteins and a number of immune response genes (Kim et al. 2000).

\section{$D m I K K \beta$ associates with DmIKK $\gamma$}

As mentioned above, the mammalian IKK $\alpha$ and IKK $\beta$ proteins are found in a high molecular weight ІкB kinase complex that includes the structural component IKK $\gamma$ or NEMO (Rothwarf et al. 1998; Yamaoka et al., 1998). To investigate the possibility that DmIKK $\beta$ is also a component of a similar kinase complex we performed a yeast two-hybrid screen using DmIKK $\beta$ as bait. A Drosophila larval cDNA library was screened, and a total of 85 independent positive clones were analyzed. All of these clones were found to contain overlapping inserts from a cDNA that encodes a Drosophila protein with homology to hIKK $\gamma$ primarily in its $\mathrm{C}$ terminus (Fig. 1A). This gene, referred to as $D m I K K \gamma$ hereafter, maps to chromosomal location 60E as determined with the BDGP P1 filter array (Kimmerly et al. 1996). Secondary structure predictions of the protein encoded by DmIKK $\gamma$ suggest the existence of several coiled-coil regions (Fig. 1A). The overall amino acid sequence homology between DmIKK $\gamma$ and hIKK $\gamma$ suggests a putative structural and functional relationship between the two proteins, especially in their C-terminal halves.

To confirm that DmIKK $\beta$ and DmIKK $\gamma$ interact, coimmunoprecipitation experiments were performed. In vitro-translated full-length DmIKK $\beta$ and Flag-tagged DmIKK $\gamma$ were both precipitated with anti-Flag beads (Fig. 1B, lane 4). Only background levels of DmIKK $\beta$ associate with the beads in the absence of Flag-DmIKK $\gamma$ (Fig. 1B, lane 3). Similarly, DmIKK $\beta$ can be coimmunoprecipitated with Flag-DmIKK $\gamma$ when the two proteins are coexpressed in Schneider cells by transfection (Fig. 1C). We conclude that DmIKK $\beta$ and DmIKK $\gamma$ interact to form a complex both in vivo and in vitro.

\section{Dominant negative DmIKKs block LPS-stimulated induction of antibacterial peptide genes}

To determine whether DmIKK $\beta$ and DmIKK $\gamma$ are involved in the activation of antibacterial genes, an LPS- 

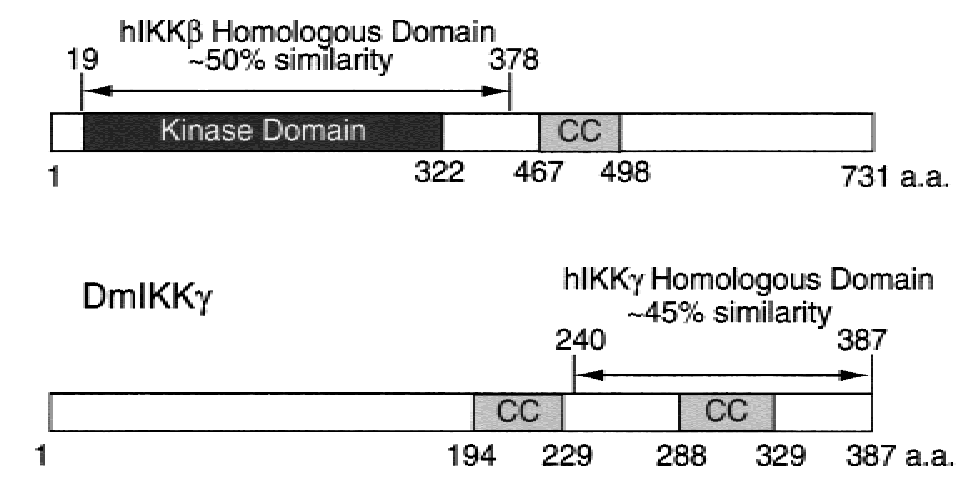

B

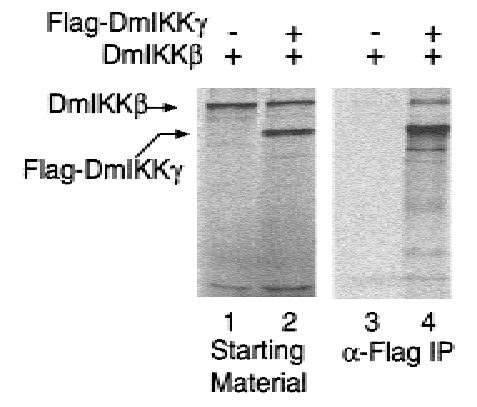

C
Figure 1. DmIKK $\beta$ and DmIKK $\gamma$ interact in vitro and in vivo. (A) Schematic representation of the Drosophila IKK homologs DmIKK $\beta$ and DmIKK $\gamma$. The N-terminal region of DmIKK $\beta$ displays significant homology to $\mathrm{hIKK} \beta$, and a predicted coiled-coil region (labeled CC) is found in a similar location to the leucine zipper of $\mathrm{hIKK} \alpha / \beta$. DmIKK $\gamma$ displays significant homology to hIKK $\gamma$ only in its C-terminal half. Like hIKK $\gamma$, DmIKK $\gamma$ has several predicted coiled-coil regions (labeled CC). (B) Coimmunoprecipitation of in vitro-translated DmIKK $\beta$ and DmIKK $\gamma$. Immunoprecipitations were performed using anti-Flag antibodies with ${ }^{35} \mathrm{~S}$-methionine-labeled in vitro-translated DmIKK $\beta$ and FlagDmIKK $\gamma$. Lanes 1 and 2 show the in vitro-translated proteins before immunoprecipitation, while lanes 3 and 4 show the Flag-immunoprecipitated DmIKK $\gamma$ and coprecipitated DmIKK $\beta$. (B) Similar coimmunoprecipitations were performed with proteins expressed by transient transfection of Schneider cells. Lane 7 shows coimmunoprecipitation of the DmIKK complex, whereas lanes 5 and 6 display controls demonstrating that precipitation of DmIKK $\beta$ requires expression of FlagDmIKK $\gamma$. (IB) Immunoblot; (IP) immunoprecipitation. inducible Drosophila cell line was engineered to express different versions of these genes. When $\mathrm{S} 2{ }^{*}$ cells are treated with LPS, the expression of antibacterial peptide genes, such as Diptericin, Cecropin, and Attacin, are induced (Samakovlis et al. 1992). Thus, S2* cells were stably transfected with plasmids that express wild-type or potentially dominant negative versions of DmIKK $\beta$ and DmIKK $\gamma$ under the control of the copper-inducible metallothionein promoter. Four cell lines were generated that express one of the following proteins: DmIKK $\beta$ wild type, DmIKK $\beta$ K50A, DmIKK $\gamma$ wild type, or DmIKK $\gamma$ 201-387. DmIKK $\beta$ K50A was chosen because similar mutations in hIKK $\alpha$ or hIKK $\beta$, which change a conserved lysine in the ATP binding domain, create dominant negative proteins (DiDonato et al. 1997; Mercurio et al. 1997; Regnier et al. 1997), whereas the DmIKK $\gamma_{201-387}$ was designed because a similarly truncated hIKK $\gamma$ acts as a dominant negative mutant in human cells (Mercurio et al. 1999). Full-length hIKK $\gamma$ can also act as a dominant negative when expressed at high levels (Li et al. 1998), presumably by titrating limiting components required for functional complex assembly.

After the addition of copper, DmIKK proteins are rapidly produced at high levels as detected by immunoblotting (data not shown). To determine whether these DmIKK proteins block LPS induction of antibacterial peptide expression in $\mathrm{S} 2^{\star}$ cells, the stable cell lines were first treated with copper to induce expression of the DmIKKs and then stimulated with LPS. As shown in the Northern blot in Figure 2, DmIKK $\beta$ K50A blocks the LPS induction of the Diptericin, Cecropin, and Attacin genes (Fig. 2, lane 12). Similarly, either full-length or truncated versions of DmIKKy are potent inhibitors of antibacterial peptide gene expression (Fig. 2, lanes 16,20). As a

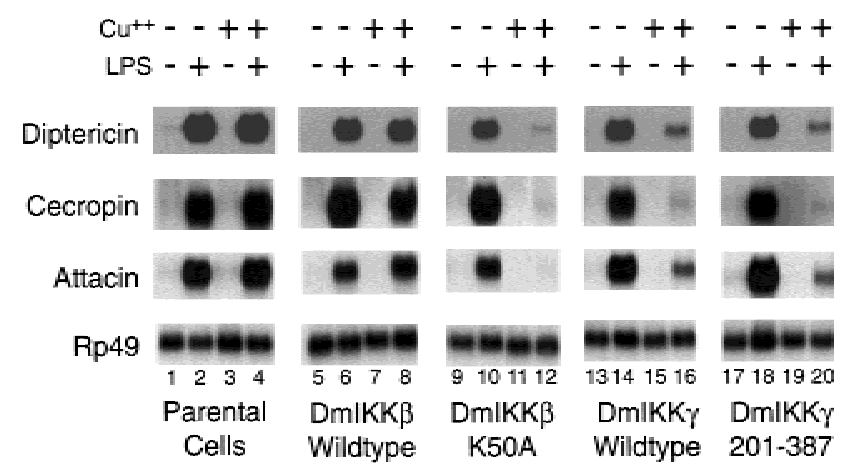

Figure 2. Dominant negative mutants of DmIKK $\beta$ or DmIKK $\gamma$ block LPS induction of antibacterial peptide gene expression. $\mathrm{S}^{*}$ * cell lines were generated that stably express various DmIKK genes under the control of a copper-inducible metallothionein promoter. The transformed gene expressed in each line is indicated below each panel. Diptericin, Cecropin, and Attacin mRNA levels were determined by RNA blotting. Total RNA was harvested from untreated cells or cells treated with LPS in the presence or absence of copper, as indicated above each panel. Rp49 levels were also probed to control for the amount of RNA recovered. Expression of DmIKK $\beta$ K50A, DmIKK $\gamma$, or DmIKK $\gamma_{201-387}$ strongly inhibits induction of the antibacterial peptide genes (lanes 12,16,20). A representative blot is shown. 
control, the first panel in Figure 2 shows that copper treatment has no effect on LPS induction of Diptericin, Attacin, or Cecropin in the parental cell line (Fig. 2, lane 4). Furthermore, when the stable lines are induced with LPS but not pretreated with copper, the antibacterial genes are induced to high levels (lanes 10,14,18). The wild-type DmIKK $\beta$ has only a marginal effect on antibacterial induction (lane 8). These data clearly show that DmIKK $\beta$ K50A, DmIKK $\gamma$ full-length, or DmIKK $\gamma_{201-387}$ potently inhibit Diptericin, Cecropin, and Attacin gene induction. By contrast, the expression of wild-type DmIKK $\beta$ slightly decreases the level of expression of these genes. We conclude that DmIKK $\beta$ and DmIKK $\gamma$ are required for the activation of antibacterial gene expression in response to LPS.

\section{Dominant negative DmIKKs block LPS-induced Relish cleavage}

As mentioned above, genetic studies have shown that the Drosophila Relish gene is essential for the antibacterial immune response (Hedengren et al. 1999). Bacterial infection or LPS treatment activates the endoproteolytic cleavage of Relish. Once cleaved, the N-terminal RHD of Relish translocates into the nucleus, where it activates the transcription of antibacterial genes (Stöven et al. 2000). Considering that the overexpression of dominant negative DmIKK $\beta$ or DmIKK $\gamma$ blocks the induction of antibacterial peptide genes, it is likely that DmIKK $\beta$ (and the DmIKK complex) functions in the signaling pathway leading to the cleavage of Relish. In order to test this possibility, the DmIKK overexpressing cell lines were employed to follow the fate of Relish protein cleavage. The stable cell lines and the parental cells were first treated with copper and then induced with LPS for 15 min. Equal amounts of total protein were analyzed by immunoblotting with an anti-Relish antibody that recognizes the C-terminal Ankyrin domain. LPS treatment of the parental cells, or any of the stable lines that were not treated with copper, results in Relish cleavage. Fulllength Relish $(\sim 110 \mathrm{kD})$ is cleaved to generate fragments of $\sim 68 \mathrm{kD}$ and $\sim 49 \mathrm{kD}$, corresponding to the N- and Cterminal fragments, respectively (e.g., see Fig. 3, lanes 1,2; Stöven et al. 2000). Expression of DmIKK $\beta$ K50A,
DmIKK $\gamma$, or DmIKK $\gamma_{201-387}$ blocks the cleavage of Relish. Full-length Relish protein persists in those samples that were treated first with copper and then with LPS (Fig. 3, lanes 12,16,20, band labeled Rel 110), whereas it is completely cleaved in the control samples not pretreated with copper (lanes 10,14,18). Similar to the analysis of antibacterial mRNAs, overexpression of wild-type DmIKK $\beta$ causes a slight accumulation of full-length Relish.

\section{Double-stranded DmIKK RNA blocks LPS-induced antibacterial gene activation and Relish cleavage but does not affect the Toll signaling pathway}

To obtain additional evidence that DmIKK $\beta$ and DmIKK $\gamma$ are required for LPS-induced antibacterial gene expression, we exploited the inhibitory effect of doublestranded RNA (dsRNA), also referred to as RNAi. The presence of gene-specific dsRNA molecules in Drosophila or Caenorhabditis elegans embryos has been shown to destabilize the cognate mRNAs (Kennerdell and Carthew 1998; Montgomery and Fire 1998; Fire 1999; Misquitta and Paterson 1999; Sharp 1999). The loss of specific mRNAs in Drosophila embryos leads to hypomorphic phenotypes, similar to mutations in the corresponding genes. Similarly, transfection of Drosophila cells in culture with specific dsRNAs can interfere with gene expression (Clemens et al. 2000; Hammond et al. 2000). Thus, dsRNA corresponding to the DmIKKy or $D m I K K \beta$ genes was synthesized in vitro and transfected into the LPS-inducible $\mathrm{S}^{*}$ cell line. Transfection of gene-specific dsRNA caused a significant reduction in the amount of the corresponding mRNA. For example, $D m I K K \gamma$ dsRNA lowers $D m I K K \gamma$ mRNA to nearly undetectable levels (see Fig. 4A), while DmIKK $\beta$ or LacZ dsRNA has no effect on DmIKKr mRNA levels. DmIKK $\gamma$ protein levels were also greatly reduced only in those cells transfected with DmIKK $\gamma$ dsRNA (Fig. 5B, left); however, it is important to note that although DmIKK $\gamma$ protein was reduced approximately 10-fold, it was still detectable after RNAi treatment. Importantly, dsRNA-mediated interference of either DmIKK $\beta$ or $D m I K K \gamma$ greatly inhibits the LPS-induced expression of antibacterial genes, such as Attacin, Cecropin, and Dip-

Figure 3. Dominant negative mutants of DmIKK $\beta$ and DmIKK $\gamma$ inhibit LPS-dependent cleavage of Relish. Extracts were prepared from cell lines expressing the copper-inducible DmIKK constructs and the control parental cell line (as labeled) $15 \mathrm{~min}$ after LPS treatment. Whole-cell lysates were analyzed by SDS-PAGE immunoblot with an antibody specific to the C-terminal Ankyrin-repeat domain of Relish. Before induction full length Relish $(110 \mathrm{kD})$ is present (lanes $1,3,5,7,9,11,13,15,17,19)$. In the parental cells, and in those cells not treated with copper, full-length Relish is barely detectable following LPS treatment, and the C-
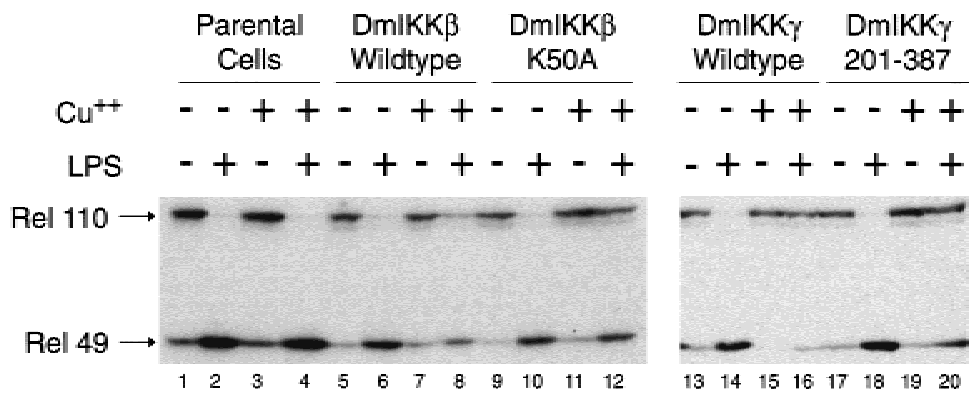

terminal 49-kD Ankyrin domain, labeled Rel 49, accumulates (lanes 2,4,6,8,10,14,18). By contrast, in the cells expressing DmIKK $\beta$ $\mathrm{K} 50 \mathrm{~A}, \mathrm{DmIKK} \gamma$, or DmIKK $\gamma_{201-387}$ the cleavage of Relish is inhibited; the full-length Relish precursor persists following LPS treatment (lanes 12,16,20). 
A

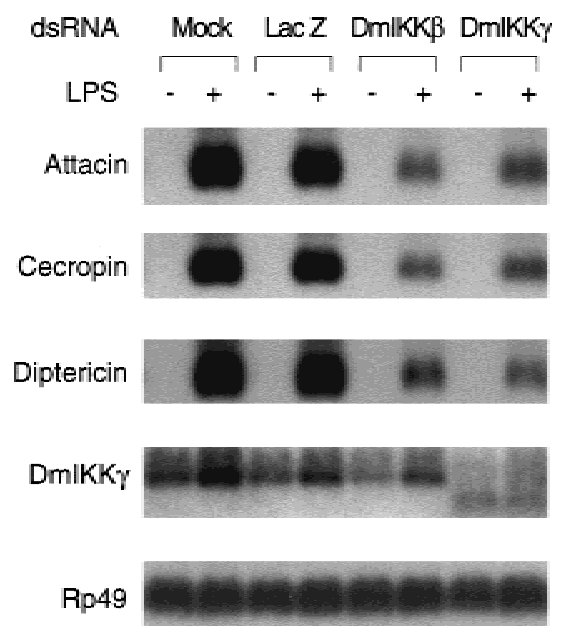

B

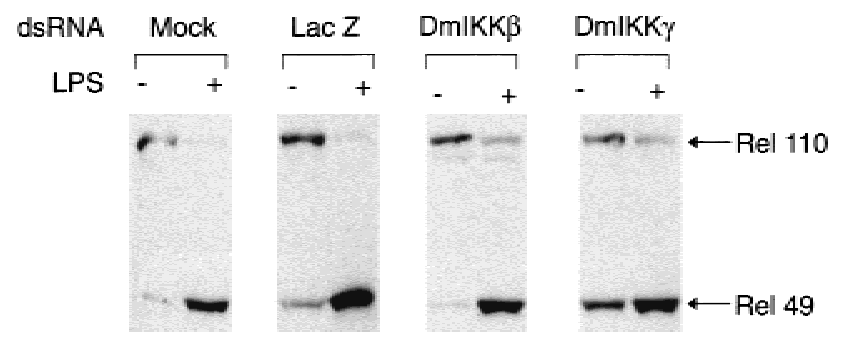

Figure 4. $D m I K K$ dsRNA specifically inhibits LPS-induced antibacterial gene expression and Relish cleavage. $(A)$ RNA from cells transfected with various dsRNA-LacZ, DmIKK $\beta$, or $D m I K K \gamma$ as labeled at the top-was analyzed by Northern blotting with probes for the antibacterial peptide genes Attacin, Cecropin, and Diptericin, as well as DmIKK $\gamma$ or $R p 49$ as a loading control. $D m I K K \gamma$ mRNA was significantly reduced only in those cells transfected with $D m I K K \gamma$ dsRNA. Furthermore, dsRNA from $D m I K K \beta$ or $D m I K K \gamma$, but not from $L a c Z$, severely inhibited LPS-mediated induction of antibacterial gene transcription. Interestingly, it is also noteworthy that LPS treatment activates the transcription of $D m I K K \gamma$. $(B)$ Whole-cell extracts from similarly treated cells were analyzed by immunoblotting with anti-Relish antibody. In either of the control cells, those not transfected with dsRNA or those transfected with LacZ dsRNA, full-length Relish (labeled Rel 110) is nearly undetectable after LPS treatment while the C-terminal Relish Ankryin-repeat-domain (labeled Rel 49) accumulates. In those cells transfected with DmIKK $\beta$ or DmIKKy dsRNA, Relish cleavage is inhibited; a significant amount of the full-length Relish protein (Rel 110) persists after LPS treatment.

tericin (Fig. 4A, top three panels). Double-stranded LacZ RNA has no effect on the expression of immune response genes, although $L a c Z$ dsRNA does inhibit the expression of a cotransfected $L a c Z$ reporter (data not shown). Furthermore, the LPS-induced cleavage of Relish is also inhibited by either $D m I K K \beta$ or $D m I K K \gamma$ dsRNA, but not by LacZ dsRNA. As shown in Figure 4B, full-length Relish protein (see band marked Rel 110) persisted after the induction with LPS only in those lanes transfected with DmIKK dsRNA. Although the inhibition of Relish cleavage seen with DmIKK RNAi is not as dramatic as that observed with the dominant negative DmIKKs (Fig. 3), it is clear that full-length Relish is not as efficiently cleaved in those cells with reduced levels of DmIKK $\beta$ or DmIKK $\gamma$. In both the dominant negative and the RNAi experiments, a stronger inhibition is always observed at the transcriptional level, as compared to that seen at the protein level. This suggests that small perturbations in the amount of the nuclear translocated Relish can have dramatic effects on the level of transcriptional activation. Small differences in the amounts of transcription factors have been shown to exhibit all-ornone effects on promoters that require the cooperative assembly of transcription enhancer complexes (Driever et al. 1989; Arnosti et al. 1996). As mentioned above and observed by others, dsRNA-mediated interference does not create a null allele. Thus, the reduced amount of Relish cleavage and antibacterial gene expression still observed in the RNAi-treated cells is most likely due to

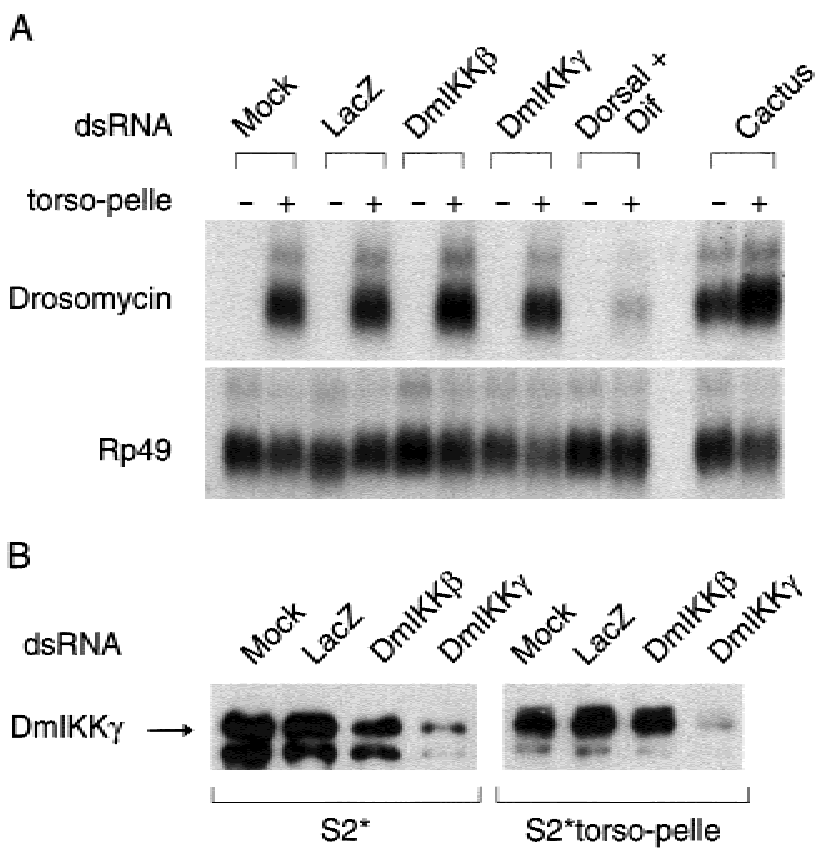

Figure 5. The Toll signaling pathway is not blocked by $D m I K K \beta$ or DmIKK $\gamma$ RNAi. (A) RNA from the S2*tpll cell line was extracted and analyzed by Northern blot analysis. The two left-most lanes show that in response to torso-pelle expression, caused by the addition of copper, Drosomycin transcription is induced. The next three pairs of lanes demonstrate, as indicated at the top, that neither $L a c Z, D m I K K \beta$, nor DmIKK $\gamma$ dsRNA significantly inhibit the torso-pelle-mediated induction of Drosomycin. However, a combination of Dif and Dorsal dsRNA blocks torso-pelle induction of Drosomycin, and Cactus RNAi causes a hyperactivation of this pathway. In the lower panel, the same samples were probed with $R p 49$ to control for the amount of RNA recovered. (B) DmIKKy dsRNA reduces the level of DmIKK $\gamma$ protein in both the S2* cell line and the S2*tpll cell line. Total cell extract $(5 \mu \mathrm{g})$ from the indicated cells, transfected with the dsRNA noted at the top, was analyzed by SDSPAGE followed by immunoblotting with the DmIKK $\gamma$ antisera. The fourth and eighth lanes show that DmIKK $\gamma$ RNAi substantially reduces the level of DmIKK $\gamma$ protein. 
the remaining DmIKKs found in these cells. Both the dominant negative and RNAi experiments show that DmIKK $\beta$ and DmIKK $\gamma$ are required for LPS-induced Relish endoproteolytic cleavage and transcriptional activation of antibacterial peptide genes in vivo.

As mentioned in the beginning, the Toll signaling pathway, which leads to Cactus degradation and activation of Dif and Dorsal, is necessary for the antifungal immune response as well as early embryonic patterning. The DmIKK $\beta / \gamma$ complex could be involved in the Toll signaling pathway in addition to its role in the antibacterial pathway. To test this possibility directly, we used the RNAi technique with a Drosophila cell line specifically engineered to assay the Toll signaling pathway. Schneider S2 * cells were stably transfected with a torsopelle fusion gene controlled by the metallothionein promoter, creating the $S 2^{\star}$ tpll cell line. Previous studies have demonstrated that fusing the transmembrane domain of torso to the pelle gene creates a constitutively active pelle kinase that can stimulate the Toll signaling pathway in fly embryos or in tissue culture cells (Grosshans et al. 1994; Galindo et al. 1995). In the S2*tpll cell line, addition of copper leads to the activation of the Toll antifungal pathway. Drosomycin transcription is induced (Fig. 5A), but Diptericin transcription is unaffected (data not shown). Transfection of dsRNA into the S2 ${ }^{\star}$ tpll cells leads to specific loss of the corresponding mRNA (data not shown) and protein. DmIKKy dsRNA causes a substantial reduction in the level of DmIKK $\gamma$ protein (Fig. 5B, right). However, neither DmIKK $\beta$ nor $D m I K K \gamma$ dsRNA blocks the torso-pelle-mediated activation of Drosomycin transcription (Fig. 5A). Importantly, RNAi can be used to modify the torso-pelle-activated pathway. A combination of Dif and Dorsal dsRNA blocks torso-pelle-induced Drosomycin induction, and Cactus dsRNA causes the hyperactivation of Drosomycin in S2 ${ }^{\star}$ tpll cell line, even without the addition of copper (Fig. 5A). Additional experiments, which utilized transient transfection to express dominant negative versions of either DmIKK $\beta$ or DmIKK $\gamma$, failed to inhibit torso-pelle- or Toll-activated signaling (data not shown). These experiments strongly argue that DmIKK $\beta$ and DmIKK $\gamma$ are not required for the Toll-mediated antifungal pathway but are required for the LPS-induced antibacterial pathway.

\section{DmIKKß phosphorylates Relish}

The finding that dominant negative DmIKKs or DmIKK RNAi can block Relish cleavage and Relish-dependent gene activation suggests that Relish may be a bona fide target of the DmIKK complex. To test this possibility, we carried out experiments to determine whether DmIKK $\beta$ or the DmIKK complex can phosphorylate Relish protein in vitro. Flag-tagged Relish was immunoprecipitated with Flag antibodies from a Schneider cell line that expresses very high levels of the epitope-tagged protein (Han and Ip 1999). Immunoprecipitated Relish was then used as a substrate with recombinant DmIKK $\beta$ in a kinase assay using $\left[\gamma^{32} \mathrm{P}\right] \mathrm{ATP}$. As shown in Figure 6A, a band the size of Relish was labeled with ${ }^{32} \mathrm{P}$ by the recombinant kinase (see Fig. 6, lanes 3,4). As a control, extracts from the parental Schneider cell line, which does not express Flag-Relish, were also used in a Flag immunoprecipitation. When these immunoprecipitates were used as substrates for DmIKK $\beta$, phosphorylation of Relish was not observed (lanes 1,2). To further demonstrate that the phosphorylated band is Relish, a similar experiment was performed using anti-Relish antibodies, instead of Flag antibodies, to precipitate Relish. Again, a band corresponding to Relish was phosphorylated in a DmIKK $\beta$-dependent manner (Fig. 6, lanes 5-8). We conclude that DmIKK $\beta$ can directly phosphorylate Relish.

To determine whether this DmIKK $\beta$ phosphorylation of Relish is specific, the ability of other, related kinases to phosphorylate Relish was tested (Fig. 6B). For these experiments, the specificity of DmIKK $\beta$ was compared to that of recombinant human IKK $\beta$ and IKK $\varepsilon$. While DmIKK $\beta$ readily phosphorylates Relish (Fig. 6, lane 2), phosphorylation was not observed with either hIKK $\beta$ or hIKK $\varepsilon$ (lanes 3,4). When these same recombinant human IKKs were used in a GST-IкB $\alpha$ kinase assay, they were both active (Fig. 6, lanes 5,6; Peters et al., 2000). Thus, the ability to phosphorylate Relish is not shared between the Drosophila and human IкB kinases. Preliminary experiments have shown that the DmIKK $\beta$ can phosphorylate the linker region between the RHD and the Ankyrin domain. Surprisingly, DmIKK $\beta$ can also phosphorylate Cactus and $I_{\kappa} \mathrm{B} \alpha$, and we have shown that this phosphorylation occurs within the $\mathrm{N}$-terminal regulatory domain, which is required for signal-dependent degradation by the proteasome (N. Silverman, N. Pandey, and T. Maniatis, unpubl.). Thus, the ability to specifically phosphorylate IкB proteins is shared by the Drosophila and human ІкB kinases, whereas only the Drosophila kinase can phosphorylate Relish. Recently the mammalian ІкB kinase complex has been shown to phosphorylate p105 (Heissmeyer et al. 1999); however, this phosphorylation leads to its degradation rather than its processing.

\section{LPS treatment activates the DMIKK complex}

To test the possibility that the activated DmIKK complex can phosphorylate Relish, an immunocomplex kinase assay was performed. First, the DmIKK complex was precipitated from an LPS-inducible Schneider cell line using an anti-DmIKK $\gamma$ antibody. This antibody recognizes the endogenous DmIKK $\gamma$ that is expressed in this cell line (Fig. 6C, lanes 1,2). Although the antiDmIKK $\beta$ antibodies are less sensitive (DmIKK $\beta$ cannot be detected in crude extracts), the DmIKK $\beta$ protein can be detected after immunoprecipitation with antiDmIKK $\gamma$ antibodies (lanes 3,4). Immunoprecipitation experiments were performed with extracts prepared from cells treated with LPS (lanes 2,4) or left untreated (lanes $1,3)$; no differences were detected, with or without LPS, in the levels of DmIKK $\beta$ or DmIKK $\gamma$ expressed and precipitated. However, LPS caused a specific increase in the level of Relish kinase activity that was detected in the 

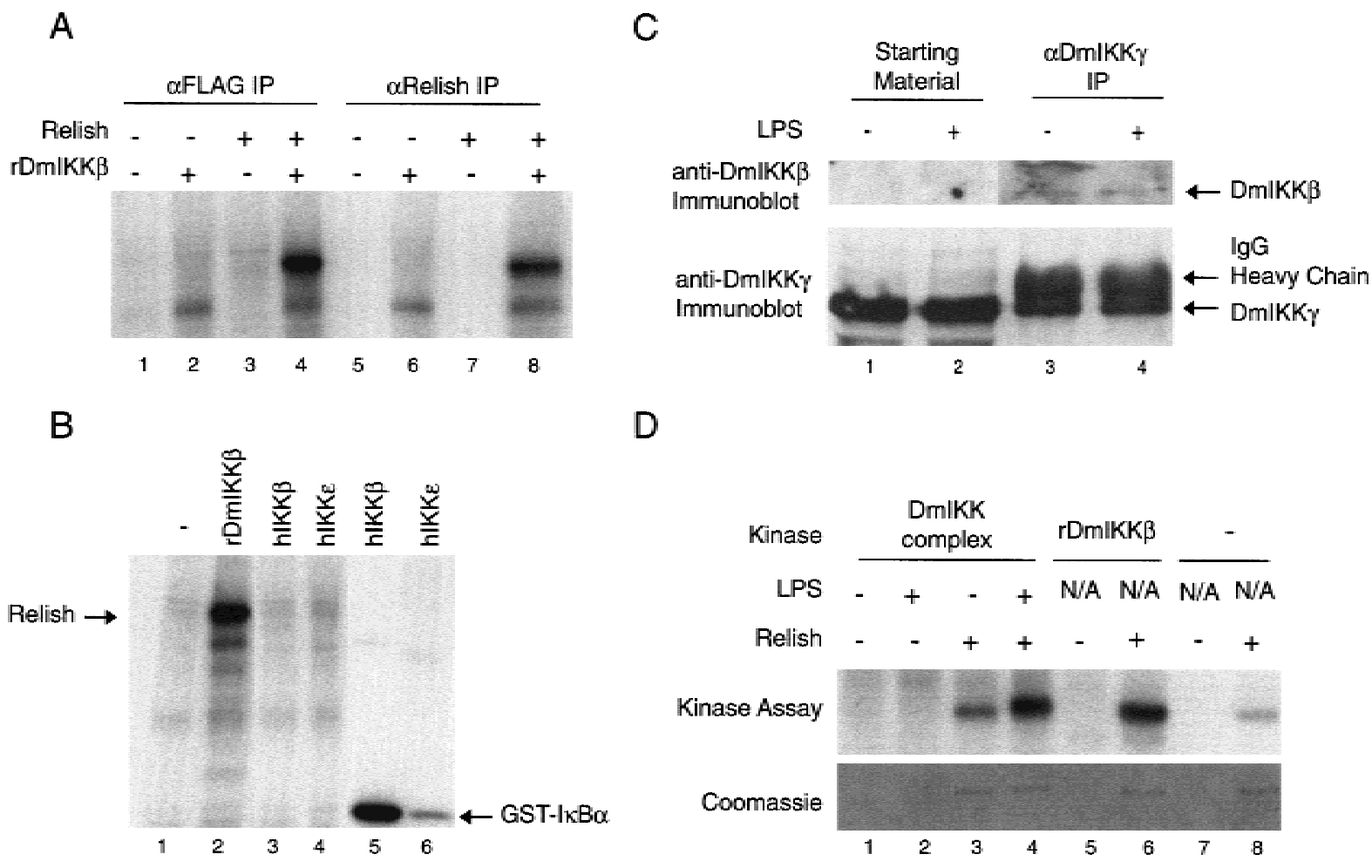

Figure 6. LPS treatment activates the Relish kinase activity of the DmIKK complex. $(A)$ Recombinant DmIKK $\beta$ phosphorylates Relish. Extracts from S2* cells (lanes 1,2,5,6) or from S2* cells that overexpress Flag-Relish (lanes 3,4,7,8) were immunoprecipitated with either Flag antibody (lanes 1-4) or Relish antibodies (lanes 5-8). This immunoprecipitate was then used as a substrate in a kinase assay with recombinant DmIKK $\beta$ and $\left[\gamma^{3}{ }^{32} \mathrm{P}\right] \mathrm{ATP}$. When extracts from the control cells were used, no phosphorylation was observed $($ lanes 1,2,5,6). By contrast, DmIKK $\beta$ phosphorylates a protein the size of Relish in those immunoprecipitates prepared from Relish overexpressing cells (lanes 4,8). When DmIKK $\beta$ is not included in the reaction, no phosphorylation is observed $($ lanes 3,7$)$. (B) DmIKK $\beta$ but not human IKK $\beta$ or IKK $\varepsilon$, can phosphorylate Relish. Relish substrate was prepared by Flag-immunoprecipitation, similar to panel $(A)$, then used in kinase assays with either DmIKK $\beta$, hIKK $\beta$, or hIKKe. Only DmIKK $\beta$ recognizes Relish as a substrate (cf. lane 2 with lanes 3,4), even though the hIKK $\beta$ and hIKKe are active as determined with a GST-IkB $\alpha$ substrate $($ lanes 5,6). (C) The endogenous DmIKK complex can be immunoprecipitated with anti-DmIKK $\gamma$ antibodies. Extracts were prepared from S2* cells before and after 15 min of LPS treatment and immunoprecipitated with anti-DmIKK $\gamma$ antibodies. Lanes 1 and 2 demonstrate that the levels of DmIKK $\gamma$ are not affected by LPS treatment. The endogenous DmIKK $\beta$ is not detectable in crude extracts. After immunoprecipitation, both DmIKK $\gamma$ and coprecipitating DmIKK $\beta$ can be detected, and LPS does not affect their interaction (lanes 3,4). (D) LPS stimulates the ability of the DmIKK complex to phosphorylate Relish. The immunoprecipitates analyzed in panel $C$ were used in a kinase reaction similar to panels $A$ and $B$. LPS treatment resulted in a much greater level of Relish kinase activity in the DmIKK complex (cf. lanes 3 and 4). Controls include lanes 1 and 2 where the Flag immunoprecipitation was performed from extracts without Flag-Relish, again demonstrating that the phosphorylated band is Relish. Lane 6 exhibits Relish phosphorylation by $\mathrm{rDmIKK} \beta$, and lane 8 exhibits the slight Relish phosphorylation activity that is often associated with Flag-immunoprecipitated Relish. Note the specific activity of the LPS-stimulated DmIKK complex is significantly higher than that of rDmIKK $\beta$ (cf. lane 4 with 6; N. Silverman and T. Maniatis, unpubl.). In the lower panel the coomassie stained gel demonstrates that the levels of Relish are very similar in all the relevant lanes.

immunoprecipitated DmIKK complex (Fig. 6D, lanes $3,4)$. Thus, the DmIKK complex that is precipitated with anti-DmIKK $\gamma$ antibodies contains an LPS-inducible Relish kinase activity. This observation supports the view that DmIKK $\beta$ and DmIKK $\gamma$ form (part of) an LPS-inducible kinase complex that phosphorylates Relish, activating its cleavage in response to LPS.

\section{Discussion}

A number of genes required for Drosophila antibacterial immunity have been identified in genetic studies, in- cluding Relish (Hedengren et al. 1999), the gene encoding the Toll-like receptor (TLR) 18-wheeler (Williams et al. 1997), the immune deficient gene (imd; Lemaitre et al. 1995) and the immune response deficient genes 1-5 (ird1-5; Wu and Anderson 1998). In this article we report the characterization of DmIKK $\beta$ and DmIKK $\gamma$, Drosophila homologs of the essential components of the human IкB kinase complex. We show that the DmIKK complex is required for the signal-induced cleavage of Relish and the induction of antibacterial peptide gene expression. Thus, DmIKK $\beta$ and DmIKK $\gamma$ play an essential role in the antibacterial immune response pathway. We also show that treatment of cells with LPS activates the 
DmIKK complex and that the activated kinase complex can then phosphorylate Relish. Consistent with this direct phosphorylation model, Relish was found to specifically interact with DmIKK $\beta$ in two-hybrid and coimmunoprecipitation assays (L. Burrack, R. Zhou, N. Silverman, T. Maniatis, unpubl.). Phosphorylated Relish may then be recognized by a yet to be identified protease that cleaves the protein between the RHD and the Ankyrin repeat domains. The N-terminal RHD of Relish then translocates into the nucleus, where it activates the expression of antibacterial genes. Additional studies will be required to identify the amino acid(s) phosphorylated in Relish and determine their role in Relish cleavage.

Using a tissue culture-based assay to specifically monitor the Toll signaling pathway, we have found that neither dominant negative DmIKKs nor DmIKK dsRNA interference inhibits the Toll pathway. Furthermore, other groups have identified mutations in both DmIKK $\beta$ and DmIKK $\gamma$, and their phenotypes in flies are consistent with our results. K. Anderson and colleagues (Y. Lu, $\mathrm{L}$. Wu, and $\mathrm{K}$. Anderson, pers. comm.) have found that ird5 encodes DmIKK $\beta$, and ird5 mutants block the activation of the antibacterial gene Diptericin but have no effect on the activation of the antifungal gene Drosomycin. Likewise, J.A. Hoffmann and colleagues have isolated a mutant, kenny, which is specifically deficient in antibacterial immunity, and they have found that kenny alleles have mutations in the $D m I K K \gamma$ gene (Rutschmann et al. 2000b). Similar to Relish mutants, mutations in ird5 and kenny inactivate the antibacterial immune response but have no effect on the dorsoventral pathway in early development and have little or no effect on the induction of antifungal peptides. On the basis of the work presented here and that from the K. Anderson and J.A. Hoffmann labs, it appears unlikely that the DmIKK $\beta / \gamma$ complex functions as the Cactus kinase required in the Toll antifungal and dorsoventral signaling pathway. Rather, our results strongly argue that the DmIKK $\beta / \gamma$ complex functions specifically in the LPS-induced Relish-dependent antibacterial pathway.

The data of Kim et al. (2000) showing that NF-кB binding activity and antimicrobial gene induction are blocked by dominant negative DmIKK $\beta$ (DLAK) are consistent with our conclusions. However, Kim et al. (2000) also showed that a dominant negative mutant of DmIKK $\beta$ blocks Cactus degradation in response to LPS treatment in cell culture. On the surface this observation would appear to contradict our results showing that the dominant negative DmIKK $\beta$ does not block Cactus degradation in the Toll signaling pathway. We note, however, that the Dif/Cactus complex can be specifically targeted in response to bacterial infection, and in this situation, the nuclear translocation of Dif is independent of the Toll signaling pathway $/ \mathrm{Wu}$ and Anderson 1998). Taken together, the experiments of Kim et al. (2000) and Wu and Anderson (1998) suggest that, in addition to its role in Relish activation, the DmIKK complex may also phosphorylate Cactus in re- sponse to bacterial infection. However, this LPS-inducible pathway must be independent from the Toll signaling pathway, which is responsible for Cactus degradation during early embryonic patterning and the antifungal immune response. What then is the function of Cactus and Dif in the antibacterial pathway? Although Dif is not strictly required for the antibacterial pathway (Rutschmann et al. 2000a), perhaps it functions to augment the transcriptional activation potential of Relish. On the other hand, Dif could be necessary for the transcriptional activation of a certain subset of the antimicrobial peptide genes in response to gram-negative bacterial infection. As neither Dif nor cactus loss-of-function mutants have strong effects on the antibacterial pathway, more detailed investigation will be required to determine if they have a significant role in this pathway. Taken together, the results presented here and by Kim et al. (2000) are consistent with the conclusion that DmIKK $\beta$ functions specifically in the antibacterial signaling pathway and not the Toll antifungal pathway. Moreover, the LPSinduced DmIKK complex may phosphorylate both Relish and Cactus, causing the cleavage and activation of Relish and possibly the degradation of Cactus and activation of Dif.

In mammalian cells, it was thought that all known NF- $\kappa \mathrm{B}$-activating signals that lead to the degradation of I $\mathrm{B}$ proteins activate a single IкB kinase complex containing IKK $\alpha$, IKK $\beta$, and IKK $\gamma$. On the basis of the data presented here, it seems likely that two ІкВ kinase activities are required in flies-one for the Toll pathway and another, DmIKK $\beta / \gamma$, for antibacterial immunity. Similarly, a recent study in mammalian systems identified an alternate IKK complex, which lacks hIKK $\alpha, \beta$, or $\gamma$ and appears to be required for NF-кB activation in response to PMA or T-cell activation (Peters et al. 2000). This complex contains an unidentified IкB kinase capable of phosphorylating serines 32 and 36 of I $\mathrm{B} \mathrm{B} \alpha$, as well as an IKK family member called IKK $\varepsilon$ (Peters et al. 2000) or IKKi (Shimada et al. 1999). Although recombinant IKK $\varepsilon / \mathrm{IKKi}$ can phosphorylate serine 36 of IкB $\alpha$, evidence suggests it may actually function as an IкB kinase kinase (IKK-kinase), activating an as yet unidentified S32/36-specific IкB kinase with which it is associated (Peters et al. 2000). A second hIKKe-like kinase known as NAK or TBK1 has also been characterized in mammals. This kinase also phosphorylates only S36 of I $\mathrm{B} \alpha$ but appears to function by activating the hIKK $\alpha /$ $\beta / \gamma$ complex directly in response to certain stimuli (Pomerantz and Baltimore 1999; Tojima et al. 2000). Remarkably, the only additional IKK-like kinase in the Drosophila DNA database is a member of the human IKK $\varepsilon /$ IKKi/TBK/NAK subfamily. Thus, a Drosophila homolog of human IKKe may be a component of the Cactus kinase complex required for Toll signal transduction during early development and the antifungal immune response, or it could function upstream of the DmIKK $\beta / \gamma$ complex in the antibacterial pathway. Experiments are in progress to test these possibilities and to characterize the Toll-inducible Cactus kinase activity. 


\section{Materials and methods}

\section{Database analysis and two-hybrid selection}

Sequence comparison was performed with BLAST, and the coiled-coil domains were predicted using the Paircoil program (Berger et al. 1995). Two-hybrid selection was performed as described (James et al. 1996) with modifications from T. Milne and B. Cali (pers. comm.). The third instar larval library (gift of S. Elledge, Baylor College of Medicine, Houston, TX) was in the $\lambda$ ACT vector (Durfee et al. 1993).

\section{Coimmunoprecipitation assays}

In vitro translation was performed following the protocol of the manufacturer (Promega). Immunoprecipitations were carried out with anti-Flag M2 agarose beads (Sigma) in IP buffer (10\% Glycerol, $20 \mathrm{mM}$ Hepes at $\mathrm{pH} 7.6,150 \mathrm{mM} \mathrm{NaCl}, 6 \mathrm{mM} \mathrm{MgCl}_{2}$, $1 \mathrm{mM}$ EDTA, 0.1\% NP-40, 0.05\% BSA, $0.5 \mathrm{mM}$ DTT). For immunoprecipitation from cells, Schneider S2* cells were first transfected by a calcium phosphate method with plasmids that express the DmIKK genes under the control of the Actin promoter (pPAC related plasmids). After $48 \mathrm{~h}$, the cells were lysed, and immunoprecipitations were performed in lysis buffer $(20$ $\mathrm{mM}$ Tris at $\mathrm{pH} 7.6,150 \mathrm{mM} \mathrm{NaCl}, 2 \mathrm{mM}$ EDTA, 10\% Glycerol, $1 \%$ Triton X-100, 1 mM DTT plus protease inhibitors) and analyzed by SDS-PAGE followed by immunoblot analysis with anti-DmIKK $\beta$ or anti-Flag antibodies. Antibodies were raised against purified recombinant protein $\operatorname{DmIKK} \beta$ in chickens using standard protocols (Covance).

\section{Stable cell lines and RNA blotting}

The various DmIKK genes and the torso-pelle gene (a gift of S. Wasserman, UCSD) were cloned into the pRmHa-3 vector by standard methods to create constructs in which they were controlled by the metallothionein promoter. These constructs were then transfected into Schneider S2* cells in conjunction with pHS-neo, or pBmIEGlacZ-BmIEGhyg (Han and Ip 1999) for the torso-pelle line, at a ratio of 50:1; stable transfectants were then selected with G418 (800 $\mu \mathrm{g} / \mathrm{mL})$, or hygromycin $(200 \mu \mathrm{g} / \mathrm{mL})$ for the torso-pelle line. Northern blot analysis for the $\mathrm{S} 2{ }^{*}$ was performed by treating the cells with copper sulfate $(500 \mu \mathrm{M})$ for $6-8$ $\mathrm{h}$, then stimulating with LPS (Sigma, 055:B5, $10 \mu \mathrm{g} / \mathrm{mL}$ ) for $3 \mathrm{~h}$. The S2*tpll cell line was pretreated with 20-hydroxy-ecdysone (Sigma), $10^{-6} \mathrm{M}$ for $24 \mathrm{~h}$ before copper treatment for $16 \mathrm{~h}$. Then RNA was extracted using Trizol reagent (BRL). The Diptericin blot was performed on samples from cells first pretreated with 20-hydroxy-ecdysone (Sigma), $10^{-6} \mathrm{M}$ for $24 \mathrm{~h}$ before copper and LPS treatment (Dimarcq et al. 1997). The Rp49 control for the Diptericin blot is not shown but is similar to that in Figure 2. Blots were probed using the ExpressHyb system (Clontech).

\section{Protein analysis}

Relish protein was examined in the stable cell lines that were treated with copper sulfate for $4 \mathrm{~h}$ and then stimulated with LPS for $15 \mathrm{~min}$. Whole-cell extracts were made with lysis buffer, and then $50 \mu \mathrm{g}$ of protein extract was loaded per lane for SDS-PAGE/ immunoblot analysis. Monoclonal Relish antibodies were used for the immunoblot (Stöven et al. 2000)

\section{RNAi experiments}

The protocol of Hammond et al. (2000) was followed. Briefly, dsRNA was synthesized from a template amplified by PCR with $\mathrm{T} 7$ promoter sequences flanking a $\sim 500$-bp fragment of the gene of interest (either DmIKK $\beta$, DmIKK $\gamma$, or LacZ), using the Ribomax kit from Promega. dsRNA was purified by phenol/ chloroform extraction and ethanol precipitation. dsRNA was transfected, along with a LacZ reporter plasmid, into S2* cells using a standard calcium phosphate method. The cells were split $24 \mathrm{~h}$ after transfection to a concentration of $0.5 \times 10^{6} / \mathrm{mL}$ and treated with $10^{-6} \mathrm{M}$ hydroxy-ecdysone $24 \mathrm{~h}$ later. After an additional $24 \mathrm{~h}$, cells were treated (or left untreated) with LPS $(10 \mu \mathrm{g} / \mathrm{mL}$ for RNA extraction or $50 \mathrm{ng} / \mathrm{mL}$ for protein extraction) for $15 \mathrm{~min}$ (for protein extracts) or $3 \mathrm{~h}$ (for RNA isolation). The RNAi experiments in the S2*tpll cell line were performed similar to that described above except that the cells were split to $1.0 \times 10^{6} / \mathrm{mL} 24 \mathrm{~h}$ after transfection and treated with $10^{-6} \mathrm{M}$ hydroxy-ecdysone. RNA and protein blots were performed as described above.

\section{Kinase assays}

His-tagged DmIKK $\beta$ was expressed in Sf9 cells using a Baculovirus expression system and purified on Ni-NTA (Graveley and Maniatis 1998). Relish was immunoprecipitated with anti-Flag antibodies or with a polyclonal Relish antibody, plus Protein G agarose, that recognizes the $\mathrm{N}$-terminal domain (S. Stöven and D. Hultmark, unpubl.). Immunoprecipitated Relish was subjected to extensive washes before being used as a substrate. Kinase reactions were performed in kinase buffer $(20 \mathrm{mM}$ Hepes at pH 7.6, $20 \mathrm{mM} \beta$-Glycerolphosphate, $10 \mathrm{mM} \mathrm{MgCl}_{2}, 50 \mathrm{mM}$ $\mathrm{NaCl}, 1 \mathrm{mM}$ DTT, $0.1 \mathrm{mM} \mathrm{NaVO}_{4}, 200 \mu \mathrm{M}$ ATP, and $5 \mu \mathrm{Ci}$ ${ }^{32} \mathrm{P}-\gamma$-ATP). hIKK $\alpha$ and hIKK $\varepsilon$ were also purified using a Baculovirus/Sf9 expression system; GST-IкB $\alpha$ was purified from Escherichia coli following standard procedures (gift of R. Peters, Harvard University, Boston, MA; Peters et al. 2000). For immunoprecipitation of the endogenous DmIKK complex, $100 \mu \mathrm{g}$ of a detergent lysate from $S 2^{*}$ cells, with or without LPS treatment $(10 \mu \mathrm{g} / \mathrm{mL}$ for $15 \mathrm{~min})$, was immunoprecipitated with $1 \mu \mathrm{L}$ of anti-DmIKK $\gamma$ antisera and Protein G beads. After washing in lysis buffer, the immunoprecipitates were equilibrated in kinase buffer and used with the substrates noted. A fraction of the immunoprecipitate was reserved for the immunoblot analysis shown in Figure 4C. DmIKK $\gamma$ antisera were raised in rabbits against recombinant DmIKK $\gamma_{1-297}$ following standard protocols (Covance).

\section{Acknowledgments}

This work was supported by the grants from the NIH to T.M. (GM29379, GM59919), from the Helen Hay Whitney Foundation to N.S., and from the Göran Gustafsson Foundation for Scientific Research and the Swedish Natural Science and Medical Research Councils to D.H. The S2 ${ }^{\star}$ tpll cell line was a gift of S. Liao. We thank T. Ip for sharing cell lines; S. Elledge for two-hybrid libraries; E. Bernstein and G. Hannon for assistance with RNAi; C. James, B. Cali, and T. Milne for two-hybrid reagents; S. Wasserman for the torso-pelle construct; and R. Peters for hIKK reagents.

The publication costs of this article were defrayed in part by payment of page charges. This article must therefore be hereby marked "advertisement" in accordance with 18 USC section 1734 solely to indicate this fact.

\section{References}

Arnosti, D.N., Barolo, S., Levine, M., and Small, S. 1996. The eve stripe 2 enhancer employs multiple modes of transcriptional synergy. Development 122: 205-214. 
Belvin, M.P. and Anderson, K.V. 1996. A conserved signaling pathway: The Drosophila toll-dorsal pathway. Annu. Rev. Cell Dev. Biol. 12: 393-416.

Berger, B., Wilson, D.B., Wolf, E., Tonchev, T., Milla, M., and Kim, P.S. 1995. Predicting coiled coils by use of pairwise residue correlations. Proc. Natl. Acad. Sci. 92: 8259-8263.

Chen, Z.J., Parent, L., and Maniatis, T. 1996. Site-specific phosphorylation of $\mathrm{I} \kappa \mathrm{B} \alpha$ by a novel ubiquitination-dependent protein kinase activity. Cell 84: 853-862.

Clemens, J.C., Worby, C.A., Simonson-Leff, N., Muda, M., Maehama, T., Hemmings, B.A., and Dixon, J.E. 2000. Use of double-stranded RNA interference in Drosophila cell lines to dissect signal transduction pathways. Proc. Natl. Acad. Sci. 97: 6499-6503.

DiDonato, J.A., Hayakawa, M., Rothwarf, D.M., Zandi, E., and Karin, M. 1997. A cytokine-responsive IкB kinase that activates the transcription factor NF-кВ. Nature 388: 548-554.

Dimarcq, J.L., Imler, J.L., Lanot, R., Ezekowitz, R.A., Hoffmann, J.A., Janeway, C.A., and Lagueux, M. 1997. Treatment of 1(2)mbn Drosophila tumorous blood cells with the steroid hormone ecdysone amplifies the inducibility of antimicrobial peptide gene expression. Insect Biochem. Mol. Biol. 27: 877-886.

Driever, W., Ma, J., Nüsslein-Volhard, C., and Ptashne, M. 1989. Rescue of bicoid mutant Drosophila embryos by bicoid fusion proteins containing heterologous activating sequences. Nature 342: 149-154.

Durfee, T., Becherer, K., Chen, P.L., Yeh, S.H., Yang, Y., Kilburn, A.E., Lee, W.H., and Elledge, S.J. 1993. The retinoblastoma protein associates with the protein phosphatase type 1 catalytic subunit. Genes \& Dev. 7: 555-569.

Dushay, M.S., Åsling, B., and Hultmark, D. 1996. Origins of immunity: Relish, a compound Rel-like gene in the antibacterial defense of Drosophila. Proc. Natl. Acad. Sci. 93: $10343-10347$.

Finco, T.S. and Baldwin, A.S. 1995. Mechanistic aspects of NF$\kappa \mathrm{B}$ regulation: The emerging role of phosphorylation and proteolysis. Immunity 3: 263-272.

Fire, A. 1999. RNA-triggered gene silencing. Trends Genet. 15: 358-363.

Galindo, R.L., Edwards, D.N., Gillespie, S.K., and Wasserman, S.A. 1995. Interaction of the pelle kinase with the membrane-associated protein tube is required for transduction of the dorsoventral signal in Drosophila embryos. Development 121: 2209-2218.

Ghosh, S., May, M.J., and Kopp, E.B. 1998. NF-кB and Rel proteins: Evolutionarily conserved mediators of immune responses. Annu. Rev. Immunol. 16: 225-260.

Graveley, B.R. and Maniatis, T. 1998. Arginine/serine-rich domains of SR proteins can function as activators of premRNA splicing. Mol. Cell 1: 765-771.

Grosshans, J., Bergmann, A., Haffter, P., and Nüsslein-Volhard, C. 1994. Activation of the kinase Pelle by Tube in the dorsoventral signal transduction pathway of Drosophila embryo. Nature 372: 563-566.

Hammond, S.M., Bernstein, E., Beach, D., and Hannon, G.J. 2000. An RNA-directed nuclease mediates post-transcriptional gene silencing in Drosophila cells. Nature 404: 293296.

Han, Z.S. and Ip, Y.T. 1999. Interaction and specificity of Relrelated proteins in regulating Drosophila immunity gene expression. J. Biol. Chem. 274: 21355-21361.

Hedengren, M., Åsling, B., Dushay, M.S., Ando, I., Ekengren, S., Wihlborg, M., and Hultmark, D. 1999. Relish, a central factor in the control of humoral but not cellular immunity in Drosophila. Mol. Cell 4: 827-837.
Heissmeyer, V., Krappmann, D., Wulczyn, F.G., and Scheidereit, C. 1999. NF-кB p105 is a target of IкB kinases and controls signal induction of Bcl-3-p50 complexes. EMBO J. 18: 4766-4778.

Hoffmann, J.A., Kafatos, F.C., Janeway, C.A., and Ezekowitz, R.A. 1999. Phylogenetic perspectives in innate immunity. Science 284: 1313-1318.

James, P., Halladay, J., and Craig, E.A. 1996. Genomic libraries and a host strain designed for highly efficient two-hybrid selection in yeast. Genetics 144: 1425-1436.

Kennerdell, J.R. and Carthew, R.W. 1998. Use of dsRNA-mediated genetic interference to demonstrate that frizzled and frizzled 2 act in the wingless pathway. Cell 95: 1017-1026.

Kim, Y.-S., Han, S.-J., Ryu, J.-H., Choi, K.-H., Hong, Y.-S., Chung, Y.-H., Perrot, S., Raibaud, A., Brey, P.T., and Lee, W.-J. 2000. Lipopolysaccharide-activated kinase, an essential component for the induction of the antimicrobial peptide genes in Drosophila melanogaster cells. J. Biol. Chem. 275: 2071-2079.

Kimmerly, W., Stultz, K., Lewis, S., Lewis, K., Lustre, V., Romero, R., Benke, J., Sun, D., Shirley, G., Martin, C., et al. 1996. A P1-based physical map of the Drosophila euchromatic genome. Genome Res. 6: 414-430.

Lee, F.S., Hagler, J., Chen, Z.J., and Maniatis, T. 1997. Activation of the IкB $\alpha$ kinase complex by MEKK1, a kinase of the JNK pathway. Cell 88: 213-222.

Lemaitre, B., Kromer-Metzger, E., Michaut, L., Nicolas, E. Meister, M., Georgel, P., Reichhart, J.M., and Hoffmann, J.A 1995. A recessive mutation, immune deficiency (imd), defines two distinct control pathways in the Drosophila host defense. Proc. Natl. Acad. Sci. 92: 9465-9469.

Lemaitre, B., Nicolas, E., Michaut, L., Reichhart, J.M., and Hoffmann, J.A. 1996. The dorsoventral regulatory gene cassette spätzle/Toll/cactus controls the potent antifungal response in Drosophila adults. Cell 86: 973-983.

Lemaitre, B., Reichhart, J.M., and Hoffmann, J.A. 1997. Drosophila host defense: Differential induction of antimicrobial peptide genes after infection by various classes of microorganisms. Proc. Natl. Acad. Sci. 94: 14614-14619.

Levashina, E.A., Langley, E., Green, C., Gubb, D., Ashburner, M., Hoffmann, J.A., and Reichhart, J.M. 1999. Constitutive activation of toll-mediated antifungal defense in serpin-deficient Drosophila. Science 285: 1917-1919.

Li, Y., Kang, J., and Horwitz, M.S. 1998. Interaction of an adenovirus E3 14.7-kilodalton protein with a novel tumor necrosis factor $\alpha$-inducible cellular protein containing leucine zipper domains. Mol. Cell. Biol. 18: 1601-1610.

Manfruelli, P., Reichhart, J.M., Steward, R., Hoffmann, J.A., and Lemaitre, B. 1999. A mosaic analysis in Drosophila fat body cells of the control of antimicrobial peptide genes by the Rel proteins Dorsal and DIF. EMBO I. 18: 3380-3391.

May, M.J. and Ghosh, S. 1998. Signal transduction through NFкB. Immunol. Today 19: 80-88.

Medzhitov, R. and Janeway, C. 2000. Fly immunity: Great expectations. Genome Biol. 1: 106.101-106.104.

Meng, X., Khanuja, B.S., and Ip, Y.T. 1999. Toll receptor-mediated Drosophila immune response requires Dif, an NF-кB factor. Genes \& Dev. 13: 792-797.

Mercurio, F., Zhu, H., Murray, B.W., Shevchenko, A., Bennett B.L., Li, J., Young, D.B., Barbosa, M., Mann, M., Manning, A., et al. 1997. IKK-1 and IKK-2: Cytokine-activated ІкB kinases essential for NF-кB activation. Science 278: 860-866.

Mercurio, F., Murray, B.W., Shevchenko, A., Bennett, B.L., Young, D.B., Li, J.W., Pascual, G., Motiwala, A., Zhu, H., Mann, M., et al. 1999. ІкB kinase (IKK)-associated protein 1, a common component of the heterogeneous IKK complex. 
Mol. Cell. Biol. 19: 1526-1538.

Misquitta, L. and Paterson, B.M. 1999. Targeted disruption of gene function in Drosophila by RNA interference (RNA-i): A role for nautilus in embryonic somatic muscle formation. Proc. Natl. Acad. Sci. 96: 1451-1456.

Montgomery, M.K. and Fire, A. 1998. Double-stranded RNA as a mediator in sequence-specific genetic silencing and co-suppression. Trends Genet. 14: 255-258.

Peters, R.T., Liao, S.-M., and Maniatis, T. 2000. IKKe is part of a novel PMA-inducible ІкB kinase complex. Mol. Cell 5: 513-522.

Pomerantz, J.L. and Baltimore, D. 1999. NF-кB activation by a signaling complex containing TRAF2, TANK and TBK1, a novel IKK-related kinase. EMBO J. 18: 6694-6704.

Regnier, C.H., Song, H.Y., Gao, X., Goeddel, D.V., Cao, Z., and Rothe, M. 1997. Identification and characterization of an IкB kinase. Cell 90: 373-383.

Rothwarf, D.M., Zandi, E., Natoli, G., and Karin, M. 1998. IKK $\gamma$ is an essential regulatory subunit of the ІкB kinase complex. Nature 395: 297-300.

Rutschmann, S., Jung, A.C., Hetru, C., Reichhart, J.M., Hoffmann, J.A., and Ferrandon, D. 2000a. The Rel protein DIF mediates the antifungal but not the antibacterial host defense in Drosophila. Immunity 12: 569-580.

Rutschmann, S., Jung, A.C., Zhou, R., Silverman, N., Hoffmann, J.A., Ferrandon, D. 2000b. Role of Drosophila IKK $\gamma$ in a Toll-independent antibacterial immune response. Nature Immunology (in press).

Samakovlis, C., Åsling, B., Boman, H.G., Gateff, E., and Hultmark, D. 1992. In vitro induction of cecropin genes-An immune response in a Drosophila blood cell line. Biochem. Biophys. Res. Comm. 188: 1169-1175.

Sharp, P.A. 1999. RNAi and double-strand RNA. Genes \& Dev. 13: 139-141.

Shimada, T., Kawai, T., Takeda, K., Matsumoto, M., Inoue, J., Tatsumi, Y., Kanamaru, A., and Akira, S. 1999. IKK-i, a novel lipopolysaccharide-inducible kinase that is related to ІкB kinases. Int. Immunol. 11: 1357-1362.

Spencer, E., Jiang, J., and Chen, Z.J. 1999. Signal-induced ubiquitination of IкB $\alpha$ by the F-box protein Slimb/ $\beta$ TrCP. Genes \& Dev. 13: 284-294.

Stöven, S., Ando, I., Kadalayil, L., Engström, Y., Hultmark, D. 2000. Activation of the Drosophila NF-kB factor Relish by rapid endoproteolytic cleavage. EMBO Reports (in press).

Tojima, Y., Fujimoto, A., Delhase, M., Chen, Y., Hatakeyama, S., Nakayama, K., Kaneko, Y., Nimura, Y., Motoyama, N., Ikeda, K., et al. 2000. NAK is an IкB kinase-activating kinase. Nature 404: 778-782.

Williams, M.J., Rodriguez, A., Kimbrell, D.A., and Eldon, E.D. 1997. The 18-wheeler mutation reveals complex antibacterial gene regulation in Drosophila host defense. EMBO J. 16: 6120-6130.

Wu, L.P. and Anderson, K.V. 1998. Regulated nuclear import of Rel proteins in the Drosophila immune response. Nature 392: 93-97.

Yamaoka, S., Courtois, G., Bessia, C., Whiteside, S.T., Weil, R., Agou, F., Kirk, H.E., Kay, R.J., and Israël, A. 1998. Complementation cloning of NEMO, a component of the IкB kinase complex essential for NF-кB activation. Cell 93: 1231-1240. 


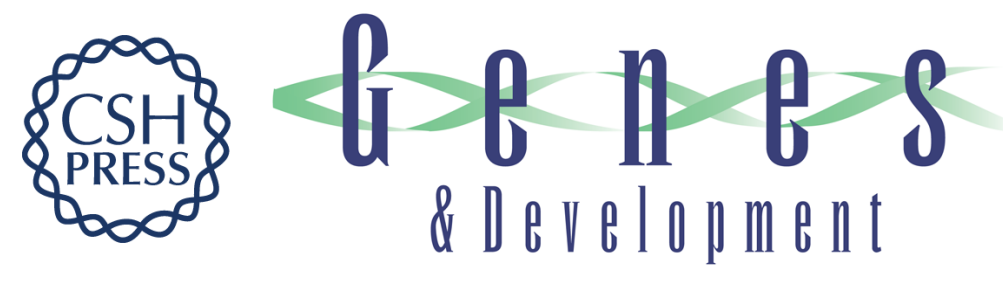

\section{A Drosophila IKB kinase complex required for Relish cleavage and antibacterial immunity}

Neal Silverman, Rui Zhou, Svenja Stöven, et al.

Genes Dev. 2000, 14:

Access the most recent version at doi:10.1101/gad.817800

References

This article cites 52 articles, 25 of which can be accessed free at:

http://genesdev.cshlp.org/content/14/19/2461.full.html\#ref-list-1

License

Email Alerting

Receive free email alerts when new articles cite this article - sign up in the box at the top

Service right corner of the article or click here.

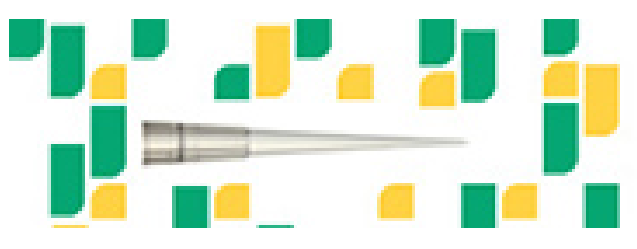

Focused on your science. 